\title{
Influence of Polyester Resin Treatment on Jute Fabrics for Geotextile Applications
}

\section{Joykrisna Saha1, Subrata Chandra Das ${ }^{2 *}$, Mahbubur Rahman"1, Md. Abu Bakar Siddiquee1, Mubarak Ahmad Khan ${ }^{3}$}

\author{
${ }^{1}$ Department of Textile Engineering, Mawlana Bhashani Science and Technology University, Tangail, Bangladesh \\ ${ }^{2}$ Pabna Textile Engineering College, Pabna, Department of Textiles, Ministry of Textiles \& Jute, Dhaka, Bangladesh \\ ${ }^{3}$ Bangladesh Atomic Energy Commission, Dhaka, Bangladesh \\ Email:joykrishnakaratia@yahoo.com, ${ }^{*}$ sc.das_mbstu@yahoo.com, mahbub.mbstu@gmail.com, \\ bakarsiddiquee_69@yahoo.com,makhan.inst@gmail.com
}

How to cite this paper: Saha, J., Das, S.C., Rahman, M., Siddiquee, M.A.B. and Khan, M.A. (2016) Influence of Polyester Resin Treatment on Jute Fabrics for Geotextile Applications. Journal of Textile Science and Technology, 2, 67-80.

https://doi.org/10.4236/jtst.2016.24009

Received: November 3, 2016

Accepted: November 15, 2016

Published: November 30, 2016

Copyright $\odot 2016$ by authors and Scientific Research Publishing Inc. This work is licensed under the Creative Commons Attribution International License (CC BY 4.0).

http://creativecommons.org/licenses/by/4.0/

\begin{abstract}
In this study, jute woven fabrics $(1 \times 1$ plain, twill, zigzag and diamond weave $)$ were manufactured from $100 \%$ raw jute yarn. The fabric specimens were treated by $5 \%, 10 \%, 15 \%, 20 \%$ and $25 \%$ unsaturated polyester resin where styrene monomer used as a solvent and 1\% methyl ethyl ketone peroxide (MEKP) was used as initiator. Two bar pressure was applied for complete wetting of the fabric by a Padder and curing was done at $130^{\circ} \mathrm{C}$ for 10 minutes. The physico-mechanical characteristics of untreated and treated samples were examined and evaluated. It was revealed that moisture content (MC) and water absorbency of the treated specimens were decreased with the increase of resin percentage (\%) in the fabrics. MC and water absorbency were maximum decreased up to $50.23 \%$ and $60.14 \%$ respectively by $25 \%$ resin treatment. On the other hand, bending length (BL), flexural rigidity (FR), flexural modulus (FM) and tensile strength (TS) were enhanced with the increase of resin percentage in the fabrics which resulted higher fabric stiffness. The maximum improvement of BL, FR, FM and TS were found to be $6.67 \%, 56.04 \%, 10.57 \%$ and $18.75 \%$ respectively in comparison to untreated sample. Soil degradation tests exhibited that $33.59 \%$ TS loss occurred for untreated specimens where only $8.04 \%$ loss of TS found for $25 \%$ resin treated one. Furthermore, jute based twill, zigzag and diamond fabrics were also treated by $10 \%, 15 \%, 20 \%$ and $25 \%$ resin, then measured their TS and compared with plain fabrics. It was revealed that plain fabrics have superior TS over other fabrics. It was also evident that TS enhanced for all the fabrics after resin treatment and maximum increase found for all the fabrics up to $25 \%$ resin treatment.
\end{abstract}

\section{Keywords}

Jute Fiber, Woven Fabrics, Polyester Resin, Tensile Strength, Geotextiles 


\section{Introduction}

Natural fibers have gained tremendous attention all over the globe in the recent decades due to the environmental concern. Natural fibers have some unique advantageous properties like low density, better specific strength, high toughness, good thermal properties, biodegradability, low cost, availability and easy to process [1]. In comparison to all natural fiber, jute is abundant as well as high staple length fiber and has excellent characteristics for textile applications with high cellulose content. Jute is basically composed of $\alpha$-cellulose, hemicelluloses, and lignin. There are also some ingredients like fats, waxes, inorganic and nitrogenous matters, and traces of pigments like $\beta$-carotene and xanthophyls [2] [3] [4]. Generally, jute fiber has versatile applications in our modern life. Jute geotextiles are going popular worldwide as technical applications. Geotextiles are permeable fabrics which have the capability to separate, filter, reinforce, or drain when used in association with soil [5]. The prime functions of jute geotextiles are separation, filtration and drainage, initial reinforcement, surface soil detachment control, improving vegetation growth or biotechnical support [6].

Usually, jute is a hydrophilic fiber i.e. strong affinity towards water and also biodegradable. Under moist condition or bacterial, mildew, fungal and insect attack, the degradation is accelerated. It can be basically swelled and degraded within six months in water and not so viable in acidic, alkaline and other chemical solutions. Quick biodegradability and high hydrophilic character of jute fiber are the main disadvantages for using as raw material for jute geotextiles. It can be possible to improve the biodegradation and hydrophobic character of jute fiber by various chemical treatments [7]-[14] without altering its environmental friendly nature. Chemical treatment such as $\mathrm{NaOH}$ [15] [16] [17] [18] [19] is a widely used method to eliminate noncellulosic materials from the natural fibers and the improvement of interfacial bonding [20] [21] [22] and mechanical characteristics of composite materials [23] [24] have been unlocked. Interfacial bonding also raised by anhydride modification [25], organosilane treatment [26] and different coupling agents [27] [28], where treatment experienced better result [29] [30]. The improvement of TS and TM of tossa jute yarn has been reported approximately $120 \%$ and $150 \%$ respectively for $25 \%$ (by weight) $\mathrm{NaOH}$ by Gassan \& Bledzki [15]. Increased weather resistance and hydrophobicity has been found by treating various concentration of $\mathrm{NaOH}$ and acetylated with or without an acid catalyst to graft acetyl groups onto the cellulose structure [31]. The effects of de-waxing with hot benzene, bleaching with $\mathrm{NaOCl}$ and $\mathrm{H}_{2} \mathrm{O}_{2}$ and delignification by $\mathrm{NaOH}$ or $\mathrm{KOH}$ treatments on the reflectance, fluorescence and tensile properties were examined and bleaching with $\mathrm{H}_{2} \mathrm{O}_{2}$ gives better result [32]. Sodium hydroxide and carboxylated styrene-butadiene copolymer based polymer latex were used for jute fiber surface modification. Alkali and polymer modifications of jute fiber improved TS and elongation at break about $41 \%$ and $34 \%$ respectively. Water absorption of jute was reduced to $108 \%$ from $210 \%$ after alkali and polymer treatment [33]. After the experimentation of various parameters 
such as alkali concentration, time, temperature, sodium silicate concentration, fiber-to-liquor ratio, auxiliaries and degumming agent, the impurities were removed as well as cellulosic materials remarkably enhanced from $65.44 \%$ to $84.78 \%$ [34].

Unsaturated polyesters resins are very popular thermoset polymer which has diverse applications in the field of plastic materials. Polyester resin has many advantageous properties such as curing at room temperature, decent mechanical characteristics and clearness. Curing has been performed by polymerization reaction which imparts crosslinking among individual linear polymer chains and by-product is not produced in comparison to other thermosetting resins, as a result, it can be easily moulded, cast and laminated at low pressures and temperatures. The reinforcement of polyester resin with cellulosic fibers has been vastly experimented such as polyester-jute [35] [36] [37], polyester-sisal [38], polyester-coir [39] [40], polyester-banana [41], polyester-pineapple leaf [42], polyester-hemp [43] and polyester-cotton-kapok [44].

The present study deals with the treatment of jute fabrics with unsaturated polyester resin mixing with styrene monomer as a solvent. MEKP is used as an initiator. The major purpose of this work was to study the effect of polyester resin on the physico-mechanical properties of jute plain fabrics so that it can be used as geotextile. After that, to study the effect of fabric structures, a comparative study of TS and soil degradation test was studied with plain, twill, zigzag and diamond fabrics.

\section{Materials and Methods}

\subsection{Materials}

Jute yarn (6 lbs/spindle, 100\% raw jute) was collected from Jute Diversified Promotion Center (JDPC), Dhaka, Bangladesh. Jute woven fabric $(1 \times 1$ weave) such as plain, twill, diamond and zigzag was manufactured in the local loom, all weaves were produced by 12 ends per inch and 13 picks per inch. Unsaturated polyester resin, styrene monomer and methyl ethyl ketone peroxide (MEKP) were collected from Dhaka, Bangladesh, made in Polymer Company Limited, Singapore.

\subsection{Methods}

\subsubsection{Polyester Resin Treatment on Jute Samples}

The solution was prepared by $5 \%, 10 \%, 15 \%, 20 \%$ and $25 \%$ polyester resin and added styrene monomer as a solvent. $1 \%$ MEKP was added in the solution as initiator. Then Jute fabric was soaked in the solution and then the fabric was being padding at two bar pressure by a padder. After that, the samples were dried at $80^{\circ} \mathrm{C}$ for 10 minutes by a mini-stenter and curing at $130^{\circ} \mathrm{C}$ for 10 minutes.

\subsubsection{Measurement of Moisture Content}

The amount of moisture in a fibre sample can be expressed as either regain or moisture content. Regain is the weight of water in a material expressed as a percentage of the oven dry weight. 


$$
\text { Moisture Regain }(\mathrm{MR})=\frac{W}{D} \times 100 \%
$$

Moisture content is the weight of water expressed as a percentage of the total weight.

$$
\text { Moisture Content }(\mathrm{MC})=\frac{W}{W+D} \times 100 \%
$$

where, $W=$ Weight of water $(A-D), A=$ Weight of the sample before, $D=$ Weight of the sample after drying. Moisture regain and content based on the oven dry mass, which for most fibres is the constant mass obtained by drying at a temperature of $105^{\circ} \mathrm{C} \pm 2{ }^{\circ} \mathrm{C}$. Constant mass is achieved by drying and weighting repeatedly until successive weighting differ by less than $0.05 \%$ [45].

\subsubsection{Water Absorbency Test}

Fabric samples $(5 \mathrm{~cm} \times 5 \mathrm{~cm})$ were immersed in a static water bath at $25^{\circ} \mathrm{C}$ for 10 minutes. Before immersion in water, the specimens were dried in an oven at $105^{\circ} \mathrm{C}$, cooled and weighed. After certain periods of time, samples were taken out from the bath and wiped using tissue paper, then weighed. The water absorption study of jute fibers was done in accordance with British standard 3449 [46]. The water absorption was calculated as Water absorption $(\%)=\left[\left(w_{2}-w_{1}\right) / w_{1}\right] \times 100$.

\subsubsection{Measurement of Flexural Properties}

This test measures the bending stiffness of a fabric by allowing a strip of the fabric to bend to a fixed angle to its own weight. Stiffness was measured with the help of fabric bending length by Shirley Fabric Stiffness Tester. The dimension of the test specimens were $25 \mathrm{~mm} \times 200 \mathrm{~mm}$. The flexural rigidity $(G)$ which is a measure of stiffness associated with handle of fabric was determined from the following relationship [47].

$$
G=W C^{3} \times 10^{3} \mathrm{mg} / \mathrm{cm}
$$

where, $C=$ Bending length, $W=$ Cloth weight in grams per square $\mathrm{cm}$. The flexural modulus or bending modulus is determined by the following formula:

Flexural or Bending modulus: $q=\left(12 \times G \times 10^{-6}\right) / \mathrm{g}^{3} \mathrm{~kg} / \mathrm{cm}^{2}$

where, $q=$ Bending modulus, $G=$ Flexural rigidity, $g=$ fabric thickness $(\mathrm{mm})$.

\subsubsection{Measurement of Tensile Strength}

TS of the test specimens were measured by Titan Universal Strength Tester. The specimen of TS was prepared according to grab test method [48]. The sample used was 4 inch $(100 \mathrm{~mm})$ wide by 6 inch $(150 \mathrm{~mm})$ long but the jaws which were used have one of their faces only 1 inch $(25 \mathrm{~mm})$ wide. This means that only the central $25 \mathrm{~mm}$ of the fabric was stressed. A line was drawn on the fabric sample 1.5 inch $(37 \mathrm{~mm})$ from the edge to assist in clamping it so that the same set of threads were clamped in both jaws. The gauge length used was 3 inch (75 $\mathrm{mm}$ ) and the speed was adjusted so that the sample was broken in $20 \pm 3$ seconds. In this test there was a certain amount of assistance from yarns adjacent 
to the central stressed area so that the strength measured was higher than for a $25 \mathrm{~mm}$ raveled strip test.

\subsubsection{Soil Degradation Tests}

All the fabric specimens were buried in soil (having at least 25\% moisture) for 6 weeks (42 days). After 6 weeks, specimens were withdrawn carefully, washed with distilled water and dried under sunlight and kept at room temperature for 24 hours and then measured the tensile strength [49].

\section{Result and Discussion}

\subsection{Mechanical Properties}

Figure 1 demonstrated that MC for $0 \%$ (untreated sample), 5\%, 10\%, 15\%, 20\% and $25 \%$ polyester resin treated jute fabrics was $13.20 \%, 12.60 \%, 10.73 \%, 10.22 \%$, $8.95 \%$ and $6.57 \%$ respectively. MC reduced up to $50.23 \%$ for $25 \%$ resin treated specimen as compared to untreated one. It was revealed that MC decreased for jute fabrics with increased in polyester resin content.

Figure 2 showed that water absorbency for $0 \%, 5 \%, 10 \%, 15 \%, 20 \%$ and $25 \%$ polyester resin treated jute fabrics were found to be $414 \%, 345 \%, 301 \%, 251 \%$,

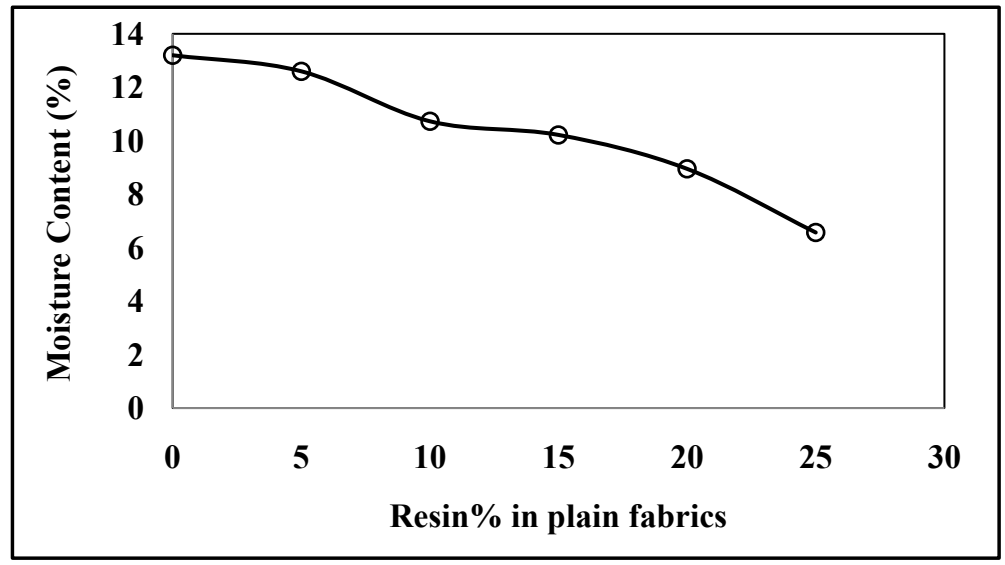

Figure 1. Moisture content (\%) of polyester resin treated jute plain fabrics.

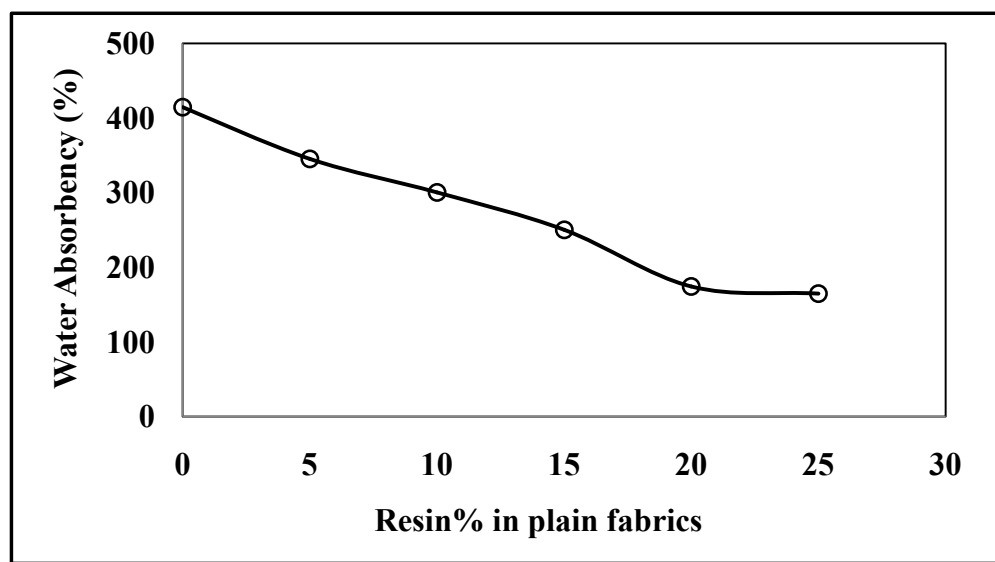

Figure 2. Water absorbency (\%) of polyester resin treated jute plain fabrics. 
$174 \%$ and $165 \%$ respectively. It was revealed that water absorbency decreased with the increase of resin\% in the fabrics and maximum decreased of water absorbency found to be $60.14 \%$ for $25 \%$ resin treated specimen as compared to untreated one. Jute fiber is hydrophilic in nature due to the presence of polar $-\mathrm{OH}$ group in its structure. The polar group formed hydrogen bond by absorbing water molecules and this induces swelling in fibers. It was clear that treated specimen retained much of its hydrophobic nature than that of the untreated specimen in case of MC and water absorbency. Polyester is a hydrophobic resin which crosslinked with jute and created strong bonding with cellulose polymer chains and it imparted a coating on the fabric surface which leads to the hydrophobicity nature. Another reason for attenuated water absorbency by the treated specimen may be a polymer filling up the void space of the fiber. Besides, better fiber-resin adhesion might be responsible for the lower tendency of water absorption as compared to untreated one.

Figure 3 exhibited that the bending length (BL) of $0 \%, 5 \%, 10 \%, 15 \%, 20 \%$ and $25 \%$ polyester resin treated samples were found to be $5.25,5.31,5.39,5.47$, 5.53 and $5.60 \mathrm{~cm}$ respectively. Flexural rigidity (FR) and flexural modulus (FM) of the fabric found to be $77.05,88.19,99.56,105.37,112.21$ and $120.23 \mathrm{mN}-\mathrm{cm}$ and $19.39,20.99,20.82,20.70,21.34$ and $21.44 \mathrm{~kg} / \mathrm{cm}^{2}$ for $0 \%, 5 \%, 10 \%, 15 \%$, $20 \%$ and $25 \%$ polyester resin treatment as shown in Figure 4 and Figure 5 respectively. Fabric BL, FR and FM gradually increased for $5 \%$ to $25 \%$ resin treated specimens. The highest improvement of BL, FR and FM were 6.67\%, 56.04\% and $10.57 \%$ respectively for $25 \%$ resin treated samples as compared to untreated one. The above observation showed that the unsaturated polyester resin affects the fabric stiffness mostly. BL increased means increases FR and FM of fabrics. The fabric appeared to increase FR or stiffness which indicated that the specimens became more hard, stiff and less flexible after polyester resin treatment. This was due to the surface coating of polyester resin around the jute fiber as well as crosslinking occurred between the fiber and resin. The mechanical properties which obtained can be suitable for polyester resin treated jute fabrics as geotextile applications.

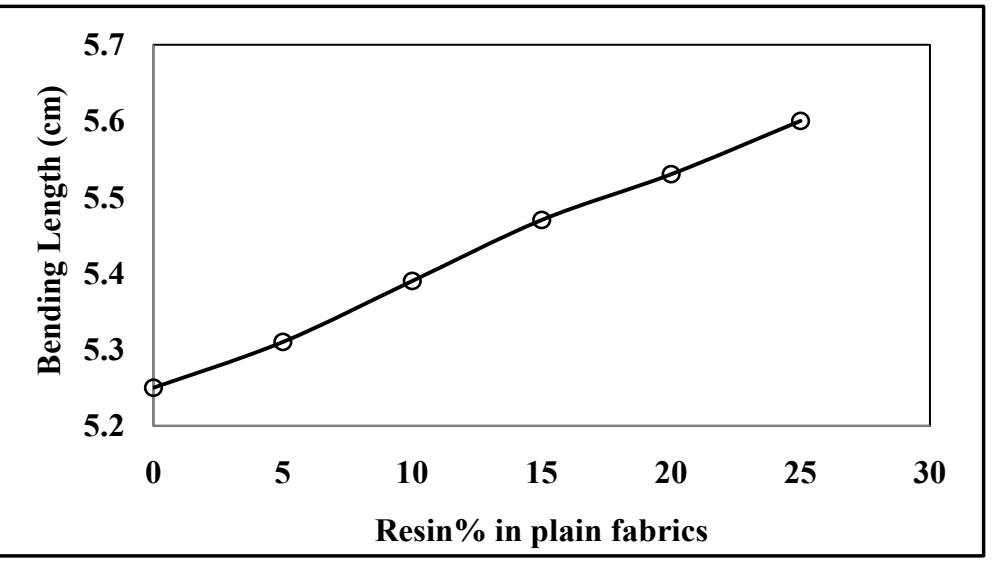

Figure 3. Bending length of polyester resin treated jute plain fabrics. 


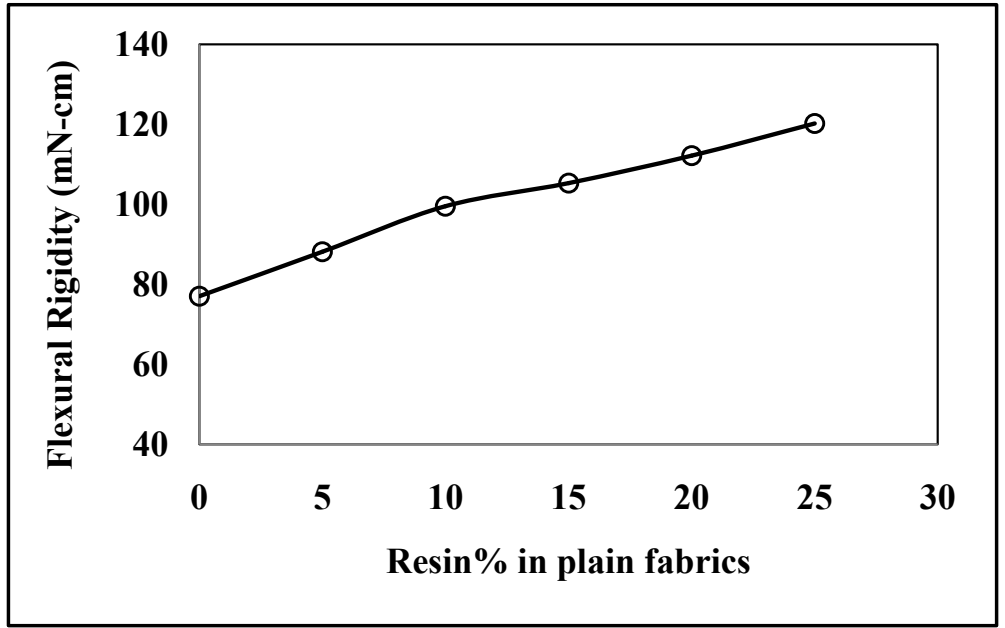

Figure 4. Flexural rigidity of polyester resin treated jute plain fabrics.

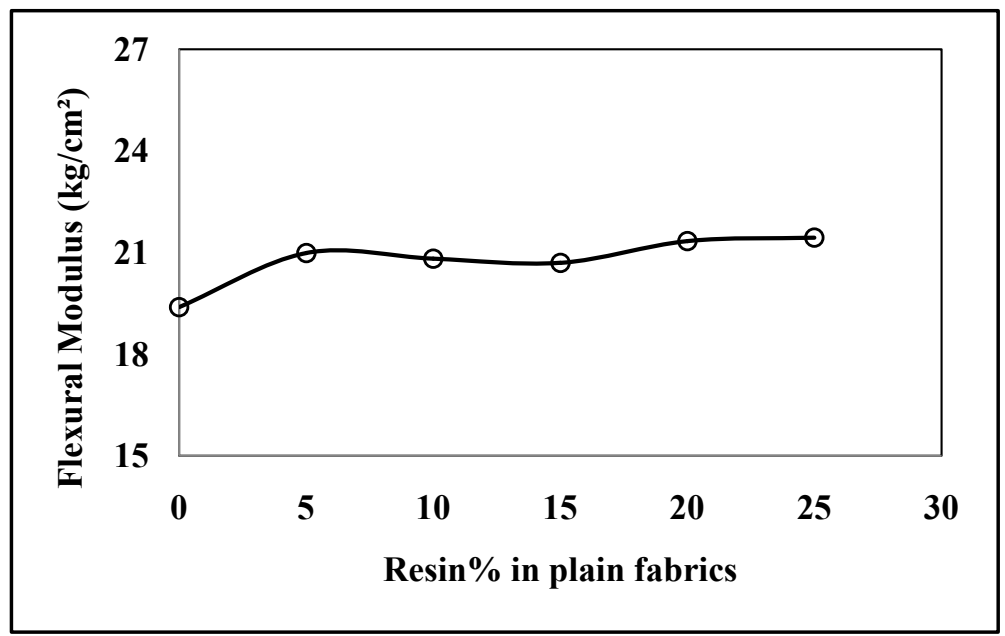

Figure 5. Flexural modulus of polyester resin treated jute plain fabrics.

\subsection{Soil Degradation}

From Figure 6, it was found that before buried in soil, the tensile strength (TS) of the test specimens were $1488.51,1540.30,1551.46,1621.88,1736.29$ and $1767.66 \mathrm{~N}$ for $0 \%, 5 \%, 10 \%, 15 \%, 20 \%$ and $25 \%$ resin treatment respectively. TS increased from $3.48 \%$ to $18.75 \%$ when treated with $5 \%$ to $25 \%$ polyester resin respectively. Thus, resin treated specimens demonstrated an increasing trend of TS and maximum increased of TS found to be $18.75 \%$ for $25 \%$ resin treatment. A successful incorporation of jute fiber and polyester resin can be achieved by full and strong interfacial contact resulting from wetting and adhesion between jute fibers and resin. Nevertheless, these factors are practically physical and these contacts between fiber surface and resin can be basically obtained by the adequate adjustment of resin-to-jute ratios, calendaring, roller pressure, minimizing the voids and micro air pockets which yielding enhanced mechanical properties. In low resin\% the TS is low, this is due to partial wetting of jute fibers where higher fiber ratio in the solution. During curing process, employing pressure or 


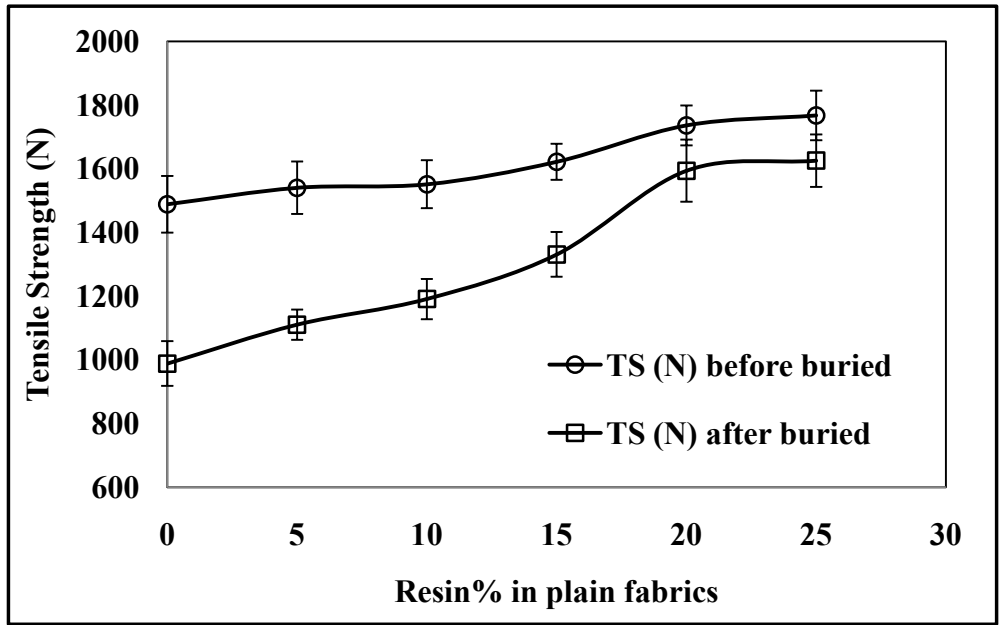

Figure 6. Tensile strength of polyester resin treated jute plain fabrics before and after buried into soil.

load improves the wetting and enhances the bonding between fiber and resin. If calendaring or load is not used, the hairy surfaces of the fiber hampered the reinforcement possibility by withstanding the contacts and leaving micro voids which resulting poor mechanical properties. The calendaring operation of jute fabric facilitates the orientation of fibers which imparted more effective packing with few micro voids that can lead to water absorption in the fiber-resin matrix interface. Albeit, intensive calendaring may cause the damage and breakage of jute fiber.

After buried in soil for 6 weeks of the test specimens, the TS were 988.56, $1110.50,1191.02,1331.26,1594.16$ and $1625.61 \mathrm{~N}$ for $0 \%, 5 \%, 10 \%, 15 \%, 20 \%$ and $25 \%$ resin treatment respectively as shown in Figure 6. Maximum loss of TS was observed $33.59 \%$ for untreated specimen and minimum loss of TS observed $8.04 \%$ for $25 \%$ resin treated specimen. It was revealed that increasing resin $\%$ reduces the possibility of strength loss of the jute fabrics during soil degradation. Jute is cellulose based natural biodegradable fiber which can be able to absorb water within a couple of minutes, indicating its strong hydrophilic properties. Cellulose has a strong tendency to degrade when buried in soil. When buried, microbial degradation takes place and water may enter into the jute fiber, thus degrade the fiber slowly and, therefore, the mechanical features of jute fabrics reduced greatly. However, 25\% resin treated specimen was highly hydrophobic and repelled water, hence keeping much of its integrity during soil degradation which extended the durability of geotextiles.

\subsection{Effect of Fabric Structures}

\subsubsection{Tensile Strength}

From Figure 7, it was observed that TS for untreated (0\% resin) plain, twill, zigzag and diamond fabrics were $1488.51,1386.68,1062.99$ and $1380.96 \mathrm{~N}$ respectively. It was revealed that plain fabric have superior TS over other fabrics and it were $7.34 \%, 40.03 \%$ and $7.79 \%$ higher TS than twill, zigzag and diamond 


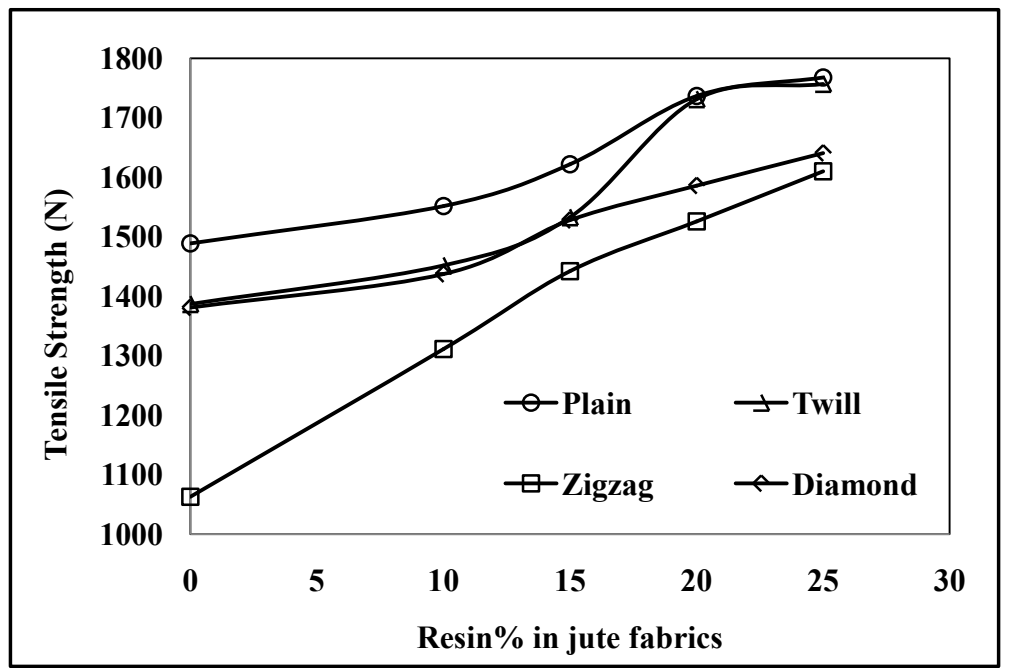

Figure 7. Effect of polyester resin treatment on the tensile strength of plain, twill, zigzag and diamond structure of jute fabrics.

fabrics respectively. Plain fabrics had uniform arrangement of warp and weft yarns and maximum interlacement points in it as a result exhibited better load bearing and stress transfer capacity than other fabrics. It was also found that after treating with $10 \%, 15 \%, 20 \%$ and $25 \%$ polyester resin, the TS of plain fabrics increased $4.23 \%, 8.96 \%, 16.67 \%$ and $18.75 \%$ respectively, and TS of twill fabrics increased $4.71 \%, 10.55 \%, 24.84 \%$ and $26.69 \%$ respectively. On the other hand, $10 \%, 15 \%, 20 \%$ and $25 \%$ resin treatment resulted in the increase of TS for zigzag fabrics were $23.33 \%, 35.69 \%, 43.56 \%$ and $51.48 \%$ respectively, and for diamond fabrics $4.08 \%, 10.65 \%, 14.84 \%$ and $18.78 \%$ respectively. The maximum increase found for all the fabrics up to $25 \%$ resin treatment which were $18.75 \%, 26.69 \%$, $51.48 \%$ and $18.78 \%$ for plain, twill, zigzag and diamond fabrics respectively. So it was revealed that all the fabrics experienced improvement of its TS after the resin treatment. Hence, treated resin specimens demonstrated increasing trends of TS and maximum increased of TS found to be $51.48 \%$ for $25 \%$ resin treatment of zigzag fabrics as shown in Figure 7.

\subsubsection{Soil Degradation}

From Figure 8, it was observed that after buried in soil for 6 weeks of the test specimens, TS for untreated ( $0 \%$ resin) plain, twill, zigzag and diamond fabrics were $988.56,870.20,735.32$ and $798.02 \mathrm{~N}$ respectively. The loss of TS were found to be $50.57 \%, 59.35 \%, 44.56 \%$ and $73.05 \%$ for plain, twill, zigzag and diamond fabrics respectively due to soil degradation of 6 weeks. It was revealed that diamond fabrics experienced maximum loss of its TS than other fabrics. The treated specimens demonstrated less degradation and retained its TS as shown in Figure 8. It was found that $10 \%, 15 \%, 20 \%$ and $25 \%$ resin treated samples showed $30.26 \%, 21.83 \%, 8.94 \%$ and $8.76 \%$ TS loss that of the untreated one for plain fabrics. Similarly, it was found to be $24.34 \%, 18.64 \%, 18.73 \%$ and $15.56 \%$ respectively for twill fabrics, $30.85 \%, 25.34 \%, 25.06 \%$ and $23.64 \%$ respectively for 


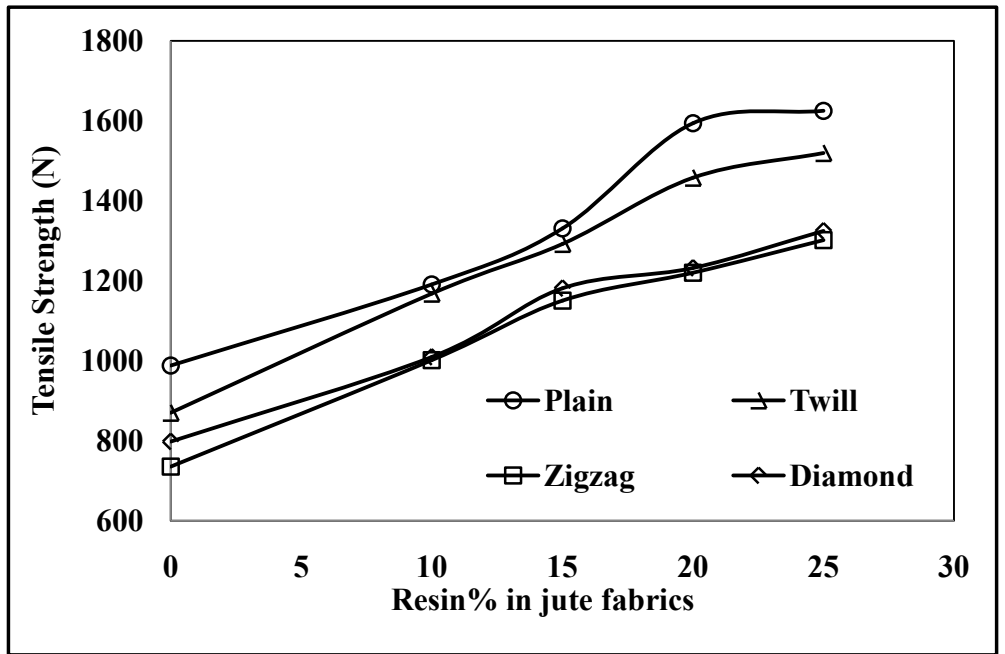

Figure 8. Effect of soil degradation on the tensile strength of polyester resin treated plain, twill, zigzag and diamond structure of jute fabrics.

zigzag fabrics, and $42.38 \%, 29.35 \%, 28.69 \%$ and $23.78 \%$ respectively for diamond fabrics. The maximum loss of TS found for untreated specimens and minimum loss of TS found for $25 \%$ resin treated specimens for all type of fabrics. In comparison to all the fabrics, plain fabrics showed the minimum loss of TS.

\section{Conclusion}

The usage of jute products is rapidly declining due to the availability of various synthetic materials which are harmful for our environment. Jute has some limitations such as extremely hydrophilic and easily biodegradable in nature. To avoid such drawbacks polyester resin treatment can be an excellent way to improve its physico-mechanical properties. Geotextile is related to soil which contains different types of fungi and other deteriorating organisms. As a result, untreated jute fabrics quickly destroyed and degraded into soil. Thus, the main purpose of using jute as a geotextile is not fulfilled. On the other hand, polyester resin treated jute fabric gives excellent performance against soil contact. In this experiment, tensile properties improved after resin treatment, and in six weeks soil degradation test, $25 \%$ resin treated samples showed approximately four times lesser degradation than that of untreated one. After the analysis of various fabric structures, it has been revealed that plain fabrics demonstrated the better tensile strength than other fabric structures. The use of these treated fabrics would ensure a better future of jute in geotextile as technical applications.

\section{References}

[1] Bledzki, A.K., and Gassan, J. (1999) Composites Reinforced with Cellulose Based Fibers. Progress in Polymer Science, 24, 221-274. https://doi.org/10.1016/S0079-6700(98)00018-5

[2] Khan, M.A., Hossain, M. and Ali, K.M.I. (1999) Jute Composite with MMA by Gamma and UV Radiations in the Presence of Additives. Journal of Applied Polymer Science, 74, 900-906. 
https://doi.org/10.1002/(SICI)1097-4628(19991024)74:4<900::AID-APP16>3.0.CO; $\underline{2-\mathrm{J}}$

[3] Khan, R.A., Haque, M.E., Khan, M.A., Zaman, H.U., Mohamad, K.J.F. and Ahmad, A. (2010) Studies on the Relative Degradation and Interfacial Properties between Jute/Polypropylene and Jute/Natural Rubber Composites. Journal of Thermoplastics Composite Materials, 25, 665-681. https://doi.org/10.1177/0892705709353723

[4] Razera, I.A.T. and Frollini, E. (2004) Composites Based on Jute Fibers and Phenolic Matrices: Properties of Fibers and Composites. Journal of Applied Polymer Science, 91, 1077-1085. https://doi.org/10.1002/app.13224

[5] Koerner, R.M. (2012) Desigining with Geosynthetics. $6^{\text {th }}$ Edition, Xlibris Publishing Co., New York.

[6] Mitchell, D.J., Barton, A.P., Fullen, M.A., Hocking, T.J., Zhi, W.B. and Zheng, Y. (2003) Field Studies of the Effects of Jute Geotextiles on Runoff and Erosion in Shropshire, UK. Soil Use and Management, 19, 182-184.

https://doi.org/10.1111/j.1475-2743.2003.tb00301.x

[7] Khan, J.A., Khan, M.A., Islam, R. and Gafur, A. (2010) Mechanical, Thermal and Interfacial Properties of Jute Fabric-Reinforced Polypropylene Composites: Effect of Potassium Dichromate. Materials Sciences and Applications, 1, 350-357. https://doi.org/10.4236/msa.2010.16051

[8] Zaman, H.U., Khan, M.A., Khan, R.A., Noor-A-Alam, M. and Bhuian, Z.H. (2012) Studies of the Physico-Mechanical Interfacial, and Degradation Properties of Jute Fabrics/Melamine Composites. International Journal of Polymeric Materials, 61, 748-758. https://doi.org/10.1080/00914037.2011.610045

[9] Kafi, A.A., Abedin, M.Z., Beg, M.D.H., Pickering, K.L. and Khan, M.A. (2006) Study on the Mechanical Properties of Jute/Glass Fiber-Reinforced Unsaturated Polyester Hybrid Composites: Effect of Surface Modification by Ultraviolet Radiation. Journal of Reinforced Plastics and Composites, 25, 575-588. https://doi.org/10.1177/0731684405056437

[10] Miah, M.J., Khan, M.A. and Khan, R.A. (2011) Fabrication and Characterization of Jute Fiber Reinforced Low Density Polyethylene Based Composites: Effects of Chemical Treatment. Journal of Scientific Research, 3, 249-259.

[11] Edeerozey, A.M., Akil, M.H., Azhar, A.B. and Ariffin, M.I.Z. (2007) Chemical Modification of Kenaf Fibers. Materials Letters, 61, 2023-2025.

[12] Pejic, B.M., Kostic, M.M., Skundric, P.D. and Praskalo, J.Z. (2008) The Effects of Hemicelluloses and Lignin Removal on Water Uptake Behavior of Hemp Fibers. Bioresource and Technology, 99, 7152-7159.

[13] Rosa, M.F., Chiou, B.S., Medeiros, E.S., Wood, D.F., Williams, T.G., Mattoso, L.H., Orts, W.J. and Imam, S.H. (2009) Effect of Fiber Treatment on Tensile and Thermal Properties of Starch/Ethylene Vinyl Copolymers/Coir Biocomposites. Bioresource Technology, 100, 5196-5202.

[14] Hill, C.A.S. and Khalil, A. (2000) Effect of Fiber Treatments on Mechanical Properties of Coir or Oil Palm Fiber Reinforced Polyester Composites. Journal of Applied Polymer Science, 78, 1685-1697. https://doi.org/10.1002/1097-4628(20001128)78:9<1685::AID-APP150>3.0.CO;2-U

[15] Gassan, J. and Bledzki, A.K. (1999) Alkali Treatment of Jute Fibers: Relationship between Structure and Mechanical Properties. Journal of Applied Polymer Science, 71, 623-629. https://doi.org/10.1002/(SICI)1097-4628(19990124)71:4<623::AID-APP14>3.0.CO; $\underline{2-\mathrm{K}}$ 
[16] Gassan, J. and Bledzki, A.K. (1999) Possibilities for Improving the Mechanical Properties of Jute/Epoxy Composites by Alkali Treatment of Fibers. Composites Science and Technology, 59, 1303-1309.

[17] Prasad, S.V., Pavithran, C. and Rohatgi, P.K. (1983) Alkali Treatment of Coir Fibers for Coir-Polyester Composites. Journal of Materials Science, 18, 1443-1454. https://doi.org/10.1007/BF01111964

[18] Ray, D. and Sarkar, B.K. (2001) Characterization of Alkali-Treated Jute Fibers for Physical and Mechanical Properties. Journal of Applied Polymer Science, 80, 1013-1020. https://doi.org/10.1002/app.1184

[19] Munawar, S.S., Umemura, K., Tanaka, K.F. and Kawai, S. (2008) Effects of Alkali, Mild Steam and Chitosan Treatments on the Properties of Pineapple, Ramie, and Sansevieria Fiber Bundles. Journal of Wood Science, 54, 28-35. https://doi.org/10.1007/s10086-007-0903-y

[20] Pickering, K.L., Efendy, M.G.A. and Le, T.M. (2016) A Review of Recent Developments in Natural Fiber Composites and Their Mechanical Performance. Composites: Part A, 83, 98-112.

[21] Valadez-Gonzalez, A., Cervantes-Uc, J.M., Olayo, R. and Herrera-Franco, P.J. (1999) Effect of Fiber Surface Treatment on the Fiber-Matrix Bond Strength of Natural Fiber Reinforced Composites. Composites Part B: Engineering, 30, 309-320.

[22] Herrera-Franco, P.J. and Valadez-Gonzalez, A. (2005) A Study of the Mechanical Properties of Short Natural Fiber Reinforced Composites. Composites Part B: Engineering, 36, 597-608.

[23] Chou, T.W. and Kelly, A. (1980) Mechanical Properties of Composites. Annual Review of Materials Science, 10, 229-259. https://doi.org/10.1146/annurev.ms.10.080180.001305

[24] Bledzki, A.K., Fink, H.P. and Specht, K. (2004) Unidirectional Hemp and Flax EPand PP-Composites: Influence of Defined Fiber Treatments. Journal of Applied Polymer Science, 93, 2150-2156. https://doi.org/10.1002/app.20712

[25] Khalil, H.P.S.A., Ismail, H., Ahmad, M.N., Ariffin, A. and Hassan, K. (2001) The Effect of Various Anhydride Modifications on Mechanical Properties and Water Absorption of Oil Palm Empty Fruit Bunches Reinforced Polyester Composites. Polymer International, 50, 395-402. https://doi.org/10.1002/pi.642

[26] Bledzki, A.K., Reihmane, S. and Gassan, J. (1996) Properties and Modification Methods for Vegetable Fibers for Natural Fiber Composites. Journal of Applied Polymer Science, 59, 1329-1336. https://doi.org/10.1002/(SICI)1097-4628(19960222)59:8<1329::AID-APP17>3.0.CO $\underline{; 2-0}$

[27] Mukherjee, R.N., Sanyal, S.K. and Pal, S.K. (1983) Studies on Jute Fiber Reinforced Composites with Polyesteramide Polyols as Interfacial Agent. Journal of Applied Polymer Science, 28, 3029. https://doi.org/10.1002/app.1983.070281003

[28] Zadorecki, P. and Flodin, P.J. (1985) Surface Modification of Cellulose Fibers. II. The Effect of Cellulose Fiber Treatment on the Performance of Cellulose-Polyester Composites. Journal of Applied Polymer Science, 30, 3971-3983. https://doi.org/10.1002/app.1985.070301003

[29] Ray, D., Sarkar, B.K., Basak, R.K. and Rana, A.K. (2004) Thermal Behavior of Vinyl Ester Resin Matrix Composites Reinforced with Alkali-Treated Jute Fibers. Journal of Applied Polymer Science, 94, 123-129. https://doi.org/10.1002/app.20754

[30] Rowell, R.M. (2001) Performance Driven Composites from Lignocellulosic Re- 
sources. Proceedings of the International Conference on Science and Technology of Composite Materials (COMAT2001), Mar Del Plata, 10-12 December 2001, 29-32.

[31] Basu, G. and Chattopadhyay, S.N. (1996) Ambient Temperature Bleaching of Jute Fiber-Its Effect on Yarn Properties and Dyeing Behavior. Indian Journal of Fiber \& Textile Research, 21, 217-222.

[32] Pan, N.C., Chattopadhyay, S.N. and Day, A. (2001) Jute Yarn Bleaching at Ambient Temperature with Different Pretreatments. Textile Asia, 3, 40-43.

[33] Chattopadhyay, D.P. (1998) Introduction, Chemistry and Preparatory Processes of Jute. Colourage, 45, 23-35.

[34] Pan, N.C., Day, A. and Mahalanabis, K.K. (1999) Chemical Composition of Jute and its Estimation. Man-Made Textiles in India, 9, 467-473.

[35] Sever, K., Sarikanat, M., Seki, Y., Erkan, G. and Erdogan, U.H. (2010) The Mechanical Properties of $\gamma$-Methacryloxypropyltrimethoxy Silane-Treated Jute/Polyester Composites. Journal of Composite Materials, 44, 1913-1924. https://doi.org/10.1177/0021998309360939

[36] Das, S.C., Paul, D., Siddiquee, M.A.B., Islam, J.M.M. and Khan, M.A. (2016) Experimental Investigation and Analysis of Mechanical Behavior of Jute Fabric Reinforced Polyester Composites, ICMIEE-PI-160-167. Proceedings of the International Conference on Mechanical, Industrial and Energy Engineering, Khulna, Bangladesh, 26-27 December 2016.

[37] Patel, R.B., Patel, K.S., Patel, R.N. and Patel, K.D. (2014) Thermal and Mechanical Properties of Modified Polyester Resin and Jute Composites. Der Chemica Sinica, 5, 47-54.

[38] Fonseca, V.M., Fernandes, V.J., de Carvalho, L.H. and d'Almeida, J.R.M. (2004) Evaluation of the Mechanical Properties of Sisal-Polyester Composites as a Function of the Polyester Matrix Formulation. Journal of Applied Polymer Science, 94, 1209-1217. https://doi.org/10.1002/app.21031

[39] Okonkwo, U.C., Chukwunyelu, C.E., Oweziem, B.U. and Ekuase, A. (2015) Evaluation and Optimization of Tensile Strength Responses of Coir Fibres Reinforced Polyester Matrix Composites (CFRP) Using Taguchi Robust Design. Journal of Minerals and Materials Characterization and Engineering, 3, 225-236. https://doi.org/10.4236/jmmce.2015.34025

[40] Rout, J., Misra, M., Tripathy, S.S., Nayak, S.K. and Mohanty, A.K. (2001) The Influence of Fiber Treatment on the Performance of Coir-Polyester Composites. Composites Science and Technology, 61, 1303-1310.

[41] Satyanarayana, K.G., Sukumaran, K., Kulkarni, A.G., Pillai, S.G.K. and Rohatgi, P.K. (1983) Performance of Banana Fabric-Polyester Resin Composites. In: Marshall, I.H., Ed., Composite Structures 2, Session XIV, Springer-Applied Science Publishers Ltd., 535-548. https://doi.org/10.1007/978-94-009-6640-6_38

[42] Devi, L.U., Joseph, K., Nair, K.C.M. and Thomas, S. (2004) Ageing Studies of Pineapple Leaf Fiber-Reinforced Polyester Composites. Journal of Applied Polymer Science, 94, 503-510. https://doi.org/10.1002/app.20924

[43] Dhakal, H., Zhang, Z. and Richardson, M. (2007) Effect of Water Absorption on the Mechanical Properties of Hemp Fibre Reinforced Unsaturated Polyester Composites. Composites Science and Technology, 67, 1674-1683.

[44] Mwaikambo, L. and Bisanda, E. (1999) The Performance of Cotton/Kapok Fabric-Polyester Composites. Polymer Testing, 18, 181-98.

[45] Hu, J. (2008) BS 4784 Determination of Commercial Mass of Consignment of Tex- 
tiles Part-I, Fabric Testing. Woodhead Publishing Series in Textiles, Cambridge, 33.

[46] Hu, J. (2008) BS 3449 Testing the Resistance of Fabric to Water Absorption (Static Immersion Test), Fabric Testing. Woodhead Publishing Series in Textiles, Cambridge, 233-234.

[47] Booth, J.E. (1968) Principles of Textile Testing. 3rd Edition, Newnes-Butterworth, London, 283-284.

[48] Hu, J. (2008) ASTM D 5034-94 Grab Test, Fabric Testing. Woodhead Publishing Series in Textiles, Cambridge, 94-95.

[49] Swain, P.K., Das, M. and Nayak, P.L. (2015) Biodegradation Studies of Chitosan-Polycaprolactone (PCL) Nanocomposite in Soil Burial Test. Middle-East Journal of Scientific Research, 23, 253-258.

\section{Scientific Research Publishing}

Submit or recommend next manuscript to SCIRP and we will provide best service for you:

Accepting pre-submission inquiries through Email, Facebook, LinkedIn, Twitter, etc. A wide selection of journals (inclusive of 9 subjects, more than 200 journals)

Providing 24-hour high-quality service

User-friendly online submission system

Fair and swift peer-review system

Efficient typesetting and proofreading procedure

Display of the result of downloads and visits, as well as the number of cited articles

Maximum dissemination of your research work

Submit your manuscript at: http://papersubmission.scirp.org/

Or contact jtst@scirp.org 